International Journal of Applied Linguistics \& English Literature

ISSN 2200-3592 (Print), ISSN 2200-3452 (Online)

Vol. 1 No. 5; September 2012 [Special Issue on General Linguistics]

\title{
The Picture of Modern Workplace Environment and Oral Communication Skills of Engineering Students of Pakistan
}

\author{
Inayatullah Kakepoto (Corresponding Author) \\ Universiti Teknologi Malaysia, Faculty of Education, Johor Bahru, Johor, 81310 Malaysia \\ Quaid-e-Awam University of Engineering Science \& Technology Nawabshah, 67480 (Sind) Pakistan \\ E-mail: inayat_kakepoto@yahoo.com
}

Hadina Habil, $\mathrm{PhD}$

Universiti Teknologi Malaysia, Language Academy, Johor Bahru, Johor, 81310 Malaysia

Noor Abidah Mohd Omar, PhD

Universiti Teknologi Malaysia, Language Academy, Johor Bahru, Johor, 81310 Malaysia

Yusuf Boon, $\mathrm{PhD}$

Universiti Teknologi Malaysia, Faculty of Education, Johor Bahru, Johor, 81310 Malaysia

S M Zafar Iqbal

Universiti Teknologi Malaysia, Faculty of Electrical Engineering, Johor Bahru, Johor, 81310 Malaysia

Received: 09-06- 2012

Accepted: 17-07- 2012

Published: 03-09- 2012

doi:10.7575/ijalel.v.1n.5p.42

URL: http://dx.doi.org/10.7575/ijalel.v.1n.5p.42

\begin{abstract}
Communication plays paramount role for engineers at workplace in this modern age of globalization and industrialization. The purpose of this study was to determine importance of oral communication and oral presentation for engineers at workplace and barriers that hindered effective oral presentation performance of engineering students for workplace environment. Thirty engineers and seven engineering students participated in this study. Purposive sampling method was used for data collection purpose. Data were analyzed both quantitatively and qualitatively. The results of the study indicated that oral communication and oral presentation plays important role for engineers at workplace and barriers for instance lack of confidence, lack of knowledge, lack of environment and lack of English language hindered effective oral presentation performance of engineering students. However, the results of this study are consistent with literature review findings on importance of oral communication and oral presentation for engineers at workplace and barriers that hamper effective oral presentation performance of engineering students.
\end{abstract}

Keywords: Modern workplace environment, oral communication skills, oral presentation barriers

\section{Background}

Non technical skills such as communication, oral communication and presentation skills play paramount role for engineers to perform workplace jobs effectively in this modern age of globalization. Globalization is not a passing phenomenon but it will stay longer in coming days and will demand more skilled workforce in terms of technical and non technical skills in order to perform workplace jobs efficiently in this new millennium of organizations. Engineering graduates equipped with effective oral communication and presentation skills promote business of organizations and satisfy customer needs at a large measure. Thus, they contribute to promote business of organizations and it impacts largely on health of organizations. Employers demand from engineering graduates to play their due role to increase workplace productivity, unfortunately their dream still has not changed into reality. This is because modern engineering graduates lack in non technical skills and employer surveys clearly state that modern engineering graduates are not ready for workplace jobs. "Engineering students prepared for 2020 and beyond must write and communicate well" (Committee on the 
International Journal of Applied Linguistics \& English Literature

ISSN 2200-3592 (Print), ISSN 2200-3452 (Online)

Vol. 1 No. 5; September 2012 [Special Issue on General Linguistics]

Engineer of 2020, 2005: 166), because good engineering require good communication (National Academy of Engineering, 2004) skills of engineering graduates such as oral communication and presentation skills. Research reveals that administrators and academicians recognize communication skills as significant skills for graduates (Gray, 2010) in order to be fit in this competitive work environment of organizations and thereby excel in job promotion ladder. In addition, industry recognizes importance of communication for engineering graduates (Korte et al., 2008). No doubt engineering graduates equipped with effective oral communication and presentation skills increase workplace productivity of organizations and employers look for graduates equipped with effective oral communication and presentation skills to hire them for workplace jobs. Thus, during the process of selection and recruitment they focus oral communication and oral presentation skills of engineering graduates. In certain instances they demand from engineering graduates to perform 5 minutes oral presentations. Sutton (2002) noted that effective communication play the role of differentiator to hire graduates for workplace jobs.

Oral presentation skills have been recognized significant skills (Aly \& Islam, 2005) for engineering graduates at workplace. This is because engineers have to perform oral presentations to keep abreast upper management of organization well informed about work progress and problems that confront organizations and decrease workplace productivity. Oral presentation skills are considered one of the best career enhancers (Polack-Wahl, 2000). Modern engineering graduates have to work in national and international organizations all over the world; therefore they have to communicate with people from public and private organizations and many other multiple stakeholders. Thus, these increased communications demand effective oral communication and presentation skills of engineering graduates to promote business of organizations at national and international level. Employers emphasize graduate oral presentation skills (Aly \& Islam, 2005) and there is a strong perception at workplace that engineering graduates equipped with effective oral presentation skills promote business of organizations and bring various financial benefits for organizations.

Gustafson et al. (1993) surveyed employers, students and alumni to obtain information regarding importance of communication skills. The results of this survey indicated that effective communication skills are required skills for graduates to obtain a job and thereby excel in job career. Employers never comprise on effective oral communication and presentation skills of engineering graduates, because engineering graduates equipped with poor oral communication and presentation skills harm interests of organizations in particular and business community in general. Thus, they never take this risk and look for graduates equipped with effective oral communication and presentations skills to hunt them for workplace jobs. A study was conducted on importance of oral presentation for engineers at workplace. The results of this study indicated that $78 \%$ working engineers were required to demonstrate oral presentations on regular basis at workplace (Keane, 1999).

Freihat Saleh et al. (2012) conducted a study on "The Picture of Workplace Oral Communication Skills for ESP Jordanian Business Graduate Employees". The results of this study revealed that $84 \%$ respondents stated that oral communication often occurs at workplace. Gray (2009) investigated importance of oral communication skills for accountancy graduates. Results of this study indicated that $91 \%$ graduates considered oral communication skills as 'very important' skills in accountancy profession. In addition, Crosling \& Ward (2002) conducted a survey on workplace communication skills for business graduates in Monash University. The findings of the survey indicated that $84 \%$ employer respondents without specifying forms of oral communication indicated that oral communication usually occurs at workplace. Moreover, Arn et al. (2010) surveyed employers on workplace communication skills. The results of this survey indicated although electronic communications were important work skills but oral communication skills were deemed more important that employees should possess for workplace jobs. Van Horn (1995) surveyed employees in New Jersey United States. The results of this survey reported that oral communication is important but it is an area in which graduates severely lack. Thus, these studies on workplace communication indicate that oral communication plays paramount role for engineers at workplace. This is because oral communication and oral presentation is an important aspect of modern workplace communication and these skills assist engineering graduates to perform workplace jobs effectively according to employer and customer satisfaction.

Reinsch and Shelby (1997) surveyed 394 business students to know challenging task for them. The results of this survey indicated that $75 \%$ business students found oral communication as most challenging task for them. This means that oral communication and oral presentation are never without problems for engineering graduates. Oral presentation is an organized way of communication that contains specific task of communication. It assists engineers to promote business of organizations and it is main objective of every employer. In fact, all major engineering organizations have established marketing departments and have appointed engineering graduates to

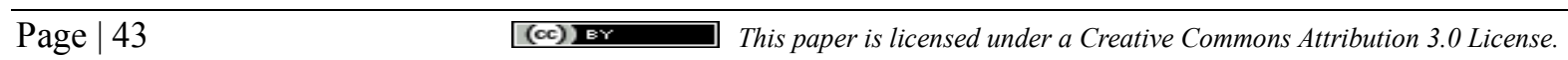


International Journal of Applied Linguistics \& English Literature

ISSN 2200-3592 (Print), ISSN 2200-3452 (Online)

Vol. 1 No. 5; September 2012 [Special Issue on General Linguistics]

visit industry sites and motivate procurement managers and employers to buy company products. Thus, engineering organizations hire engineering graduates equipped with effective oral communication and presentation skills. Anderson \& Bolt (2008) noted that modern graduates lack in presentation skills, although it is an important aspect of modern workplace. This paper focuses importance of oral communication and oral presentation for engineers at workplace and barriers that hinder effective oral presentation performance of engineering students of Pakistan. An abundance of literature is available on workplace communication and oral presentation barriers but it is scarce and fragmented. In addition, it does not present any clear picture of barriers that hinder effective oral presentation performance of engineering students. The findings of this study would contribute to existing body of communication literature on workplace oral communication and oral presentation barriers that obstruct effective oral presentation performance of engineering students.

\section{Research Methodology}

The research approach adopted for this study was mixed methods research based on questionnaire survey and semi structured interviews conducted with engineering students. Thirty engineers from workplace and 7 engineering students from engineering universities of Pakistan participated in this study. Purposive sampling method was used since respondents were selected on specific criteria of engineers with minimum 5 years work experience and only final year engineering students. The rationale for selection of engineers with 5 years work experience was based on the understanding that these engineers would be better able to provide appropriate feedback regarding the importance of oral communication and oral presentation for engineers at workplace. On the other hand, final year engineering students were selected on the understanding that they would be better able to provide feedback relating to barriers that hinder their effective oral presentation performance. Purposive sampling is a non probabilistic sampling method that is used for specific purpose (Singleton \& Straits, 2005). The questionnaire used for this study contained two parts. First part included demographic information asking about gender, qualification, age, field of discipline, nature of job and work experience. Second part of this questionnaire contained statements relating to importance of oral communication and oral presentation for engineers at workplace. A 5 point likert scale ranging 1 to 5 where " 1 " indicates "strongly disagree" to " 5 " for "strongly agree" was used.

\section{Data Analysis}

Data were analyzed both quantitatively and qualitatively. Quantitative data were analyzed by using Statistical package for Social Sciences (SPSS) to draw percentages for agreement and disagreement level of respondents for the variables included in the questionnaire. In addition, qualitative data in terms of semi structured interviews were analyzed through three techniques data reduction, data display, and conclusion drawing and verification as suggested by Miles \& Huberman (1994).

\subsection{Quantitative Findings}

The research findings provided valuable insights on importance of oral communication and oral presentation for engineers at workplace. For this dimension $5 \%$ engineers strongly disagreed, $6 \%$ disagreed, $11 \%$ responded neutral, $39 \%$ agreed, and $39 \%$ strongly agreed that oral communication and oral presentation plays paramount role for engineers at workplace.

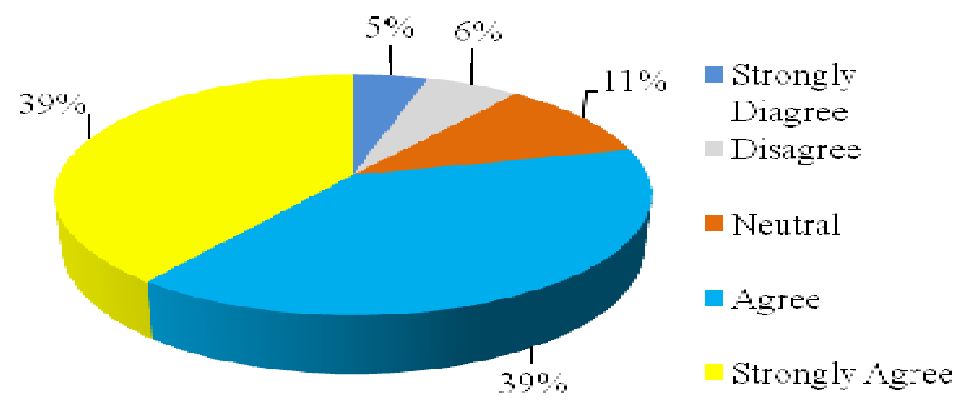

Figure 1: Importance of oral communication and oral presentation for engineers at workplace 
International Journal of Applied Linguistics \& English Literature

ISSN 2200-3592 (Print), ISSN 2200-3452 (Online)

Vol. 1 No. 5; September 2012 [Special Issue on General Linguistics]

\subsection{Qualitative Findings}

On qualitative part researchers interviewed seven engineering students to obtain in depth views on barriers that hinder their effective oral presentation performance. Some key qualitative findings are discussed as:

A comment by engineering student 1 was:

"Well biggest problem I have that I am not very used to...oral presentation side. I have never done such kind of presentation before huge audience, so there is the biggest problem I am having lack of confidence whenever I come before huge audience my legs start shivering ...that is my biggest problem lack of confidence".

This engineering student indicated that he is not habitual for taking part in oral presentations. This is because he has never performed such kind of presentation prior to this presentation. This shows that it was first presentation of this engineering student during his four year engineering degree program.

This finding is very interesting for the researcher because during four year engineering degree program this engineering student did never perform any oral presentation. This means communication teachers do not provide oral presentation opportunities to all students of the class and only few students participate in oral presentations. It is envisaged that communication teachers provide few oral presentations to selected engineering students during semester in order to cover the syllabus designed for the subject. It further indicates that oral presentation is not the part of engineering communication curriculum taught to engineering students. This respondent further indicated that he faces lack of confidence and due to this barrier his legs start shivering when he appears before audience. Thus, lack of confidence is the biggest problem of this engineering student that hampers his effective oral presentation performance.

A comment by engineering student 2 was:

"There are two reasons for that one is lack of knowledge and other is lack of confidence but main one is lack of knowledge".

This respondent indicated that there are two barriers that hinder his effective oral presentation performance for instance lack of knowledge and lack of confidence. However, main barrier of this engineering student is lack of knowledge that hinders his effective oral presentation performance.

A comment by engineering student 3 was:

"...we need environment, we should have knowledge...so we should have knowledge... environment must be there".

This respondent indicated that there are 2 barriers that hinder his effective oral presentation performance. They are poor environment and lack of knowledge. This finding is very interesting for the researcher that this engineering student complained about poor environment of his class or institution. This indicates that language or communication teachers do not promote oral presentation activities in the class. Thus, poor environment or poor knowledge are barriers that hinder effective oral presentation performance of this engineering student.

A comment by engineering student 4 was:

"I have lot of things for explanation but cannot, because I have no potential in front of audience".

This respondent indicated that he has lot of things to say but he cannot say due to various barriers. This is a very interesting finding for the researcher. This is because a final year engineering student who is ready to join the workplace cannot explain only barriers that hinder his effective oral presentation performance.

It is envisaged that this engineering student will face same barriers at workplace which is neither in the better interest of this student nor his organization. This shows that engineering universities of Pakistan do not properly train engineering students in non technical skills such as oral communication and oral presentation skills and main focus is merely on technical skills. Thus, employers usually complain that modern engineering graduates are not ready for workplace jobs. This indicates a gap between required skills and acquired skills of engineering students from engineering universities of Pakistan. This tends that this student has been neglected by teachers to take part in classroom oral presentations. Thus, language or communication teachers should provide oral presentation opportunities to all engineering students in order to assist them to overcome barriers that hinder their effective oral presentation performance prior to joining the workplace.

A comment by engineering student 5 was: 
International Journal of Applied Linguistics \& English Literature

ISSN 2200-3592 (Print), ISSN 2200-3452 (Online)

Vol. 1 No. 5; September 2012 [Special Issue on General Linguistics]

"Oral presentation yes my English language talking...and some little bit lack of confidence and some little bit we can say lack of knowledge...some hesitation we can say...we have to confuse that some students have questions in their mind ...we are also confuse chances of confusing so reason".

This respondent indicated that English language, lack of confidence, lack of knowledge, hesitation, and confusion are barriers that hinder his effective oral presentation performance. This indicates that this engineering student has been provided few oral presentations during his stay at the university. Thus, it is envisaged that these barriers will influence his job employment and job performance following graduation at workplace.

A comment by engineering student 6 was:

"Basically oral presentation barriers are talking power, our English our way of speaking how to present, these are very basic barriers..."

This respondent stated that poor oral communication skill and English language are barriers that hinder his effective oral presentation performance.

A comment by engineering student 7 was:

“...feel low knowledge when I count low knowledge is a barrier for me ... I cannot present well ... when I do not have knowledge, I feel some stress upon me..."

This engineering student indicated that poor knowledge, poor oral communication skill, and stress are barriers that hinder his effective oral presentation performance. This indicates that due poor practice of oral presentations engineering students face various barriers that hinder their effective oral presentation performance.

In sum engineering students face various barriers that hinder their effective oral presentation performance. It is never in the better interest of engineering students since modern workplace environment has become very competitive to obtain a job. This shows skills gap between the acquired skills and the required skills of engineering students.

\section{Discussion}

The results of this study reported that oral communication and oral presentation plays paramount role for engineers at workplace. Van Horn (1995) surveyed employees in New Jersey United States. The results of this survey reported that oral communication is important at workplace but it is an area in which graduates severely lack. Freihat Saleh et al. (2012) conducted a study on "The Picture of Workplace Oral Communication Skills for ESP Jordanian Business Graduate Employees". The results of this study revealed that 84\% respondents agreed that oral communication is an important aspect of modern workplace.

The results of this study further indicated that barriers such as lack of confidence, lack of knowledge, lack of environment, and lack of English language hinder effective oral presentation performance of engineering students. A study was conducted by Razdun Noor et al. (2011) on "Technical oral presentations in English: Qualitative analysis of Malaysian engineering undergraduates' sources of anxiety". The results of this study indicated that English language was a barrier for engineering students to perform effective oral presentations. Lack of confidence decreases academic performance of students (Fook et al., 2011; Aryana, 2010; Harris, 2009). Oral presentation is a problem for students when it is presented in English language (Zareva's, 2011).

It is envisaged that oral presentation barriers of engineering students tend to be due to poor oral communication skill trainings provided to engineering students during study time. Thus, engineering students are not satisfied from classroom environment. This indicates that communication or language teachers fail to provide ample opportunities of oral presentations to engineering students to assist them to overcome barriers that hinder their effective oral presentation performance. In addition, findings of this study indicate skills gap between the acquired skills and required skills of engineering graduates. Oral communication and oral presentation plays paramount role for engineers to perform workplace jobs effectively at workplace, on the other hand, engineering students of Pakistan severely lack in these skills. As a result, these barriers will affect their job performance of these engineering students which will lead poor productivity of organizations. In view of this, it is suggested that industry and engineering universities of Pakistan should establish strong collaboration in order to prepare better human capital not only for local but global organizations which is prime demand of this modern age. It is envisaged that this collaboration will assist to overcome increasing unemployment in engineering profession of Pakistan. 
International Journal of Applied Linguistics \& English Literature

ISSN 2200-3592 (Print), ISSN 2200-3452 (Online)

Vol. 1 No. 5; September 2012 [Special Issue on General Linguistics]

\section{Conclusion}

This study investigated importance of oral communication and oral presentation for engineers at workplace and barriers that hindered effective oral presentation performance of engineering students. The results of this study indicated that oral communication and oral presentation plays paramount role for engineers at workplace and barriers such as lack of confidence, lack of knowledge, lack of environment, and lack of English language hindered effective oral presentation performance of engineering students. Truly speaking, these barriers are mainly due to poor oral communication and oral presentation skill trainings provided to engineering students. Thus, engineering universities of Pakistan should focus non technical skills such as oral communication and oral presentation skills of engineering students to prepare them better human capital for the workplace. If necessary they should add more communication courses in engineering curriculum that focus oral communication and oral presentation skills of engineering students. Thus, it is in the better interest of engineering universities of Pakistan because industry is the biggest employer of engineering students.

\section{Further Study}

This study found that oral communication and oral presentation play paramount role for engineers at workplace and barriers hinder effective oral presentation performance of final year engineering students. The following research should be considered for further study to prepare better engineers equipped with technical and non technical skills for modern workplace.

1. This survey focused engineers on importance of oral communication and oral presentation for engineers at workplace. Their insight might add a dimension that can be used to design communication skills curriculum for engineering students.

2. This survey focused oral presentation barriers of final year engineering students. Their insight might add a dimension that can be used to prepare future engineers skilled in terms of non technical skills for local as well as global organizations.

3. Research engineering education to discover which oral communication skills are important for engineering graduates to perform workplace jobs effectively in this competitive work environment of organizations. Results may benefit adaptation to the changing oral communication skill needs of engineering graduates and the development of oral communication skills of engineering students prior to joining the workplace.

4. Research engineering curriculum and degree of oral communication skills incorporated into engineering curriculum for modern engineering students. Results may indicate that language or communication teachers focus oral communication and presentation skills of engineering students prior to joining the workplace.

\section{References}

Aly, I., \& Islam, M. (2005). Factors affecting oral communication apprehension among business students: An empirical study. The Journal of American Academy of Business, Cambridge, 2, 98-103.

Anderson, R. (2008). Maximizing final exam scores in quantitative courses, Mountain Plains Journal of Business and Economics, 9(2), 85-95.

Arn, J., Kordsmeier, B., \& Gatlin-Watts, R. (2010). A survey of workforce communication skills. Journal of Organizational Culture, Communications and Conflict, 6(1-2), 1. Retrieved from Gale: Academic One File (Power Search) database.

Aryana, M. (2010). Relationship between Self-Esteem and Academic Achievement amongst Pre-University Students. Journal of Applied Sciences, 10 (20), 2474-2477

Crosling, G. \& Ward, I. (2002). Oral communication: The workplace needs and uses of business graduate employees. English for Specific Purposes, 21, (1), 41-57.

Fook, C et al. (2011). Analyzing Factors Associated with Students" Oral Test Performance. The International 
International Journal of Applied Linguistics \& English Literature

ISSN 2200-3592 (Print), ISSN 2200-3452 (Online)

Vol. 1 No. 5; September 2012 [Special Issue on General Linguistics]

Journal of Educational and Psychological Assessment, 9(1), 27-46

Harris, S. (2009). The relationship Between Self-Esteem and Academic Success among African American

Students in the Minority Engineering Program at a Research Extensive University in the Southern Portion of the United States. Doctoral Dissertation. Louisiana State University.

Saleh Freihat and Khalaf Al-Machzoomi (2012). The Picture of Workplace Oral Communication Skills for ESP

Jordanian Business Graduate Employees. International Journal of Business, Humanities and TechnologyVol. 2

No. 1; January 2012

Gray, E. (2009). Specific oral communication skills desired in new accountancy graduates. Business

Communication Quarterly, 73, 40-67, first published on January 28, 2010.

Gustafson, L.V., Johnson, J.E., and D.H. Hovey (1993). "Preparing Business Students-Can We Market Them Successfully?” Business Education Forum, Volume 37, Number 4, 23-26.

Keane, A. and Gibson, I.S. (1999). Communication trends in engineering firms: implications for undergraduate engineering courses. International J. of Engg. Educ, 15, 2, 115-121

Korte, S. Sheppard, and W. Jordan. (2008, Jun. 22-25). A qualitative study of the early work experiences of recent graduates in engineering, in Proc. ASEE Annual Conference.

Mathew B. M. \&, Michael, H. A. (1994). Qualitative Data Analysis. An expanded sourcebook (2nd edition) Sage Publication

Noor Raha Mohd Radzuan, Sarjit Kaur (2011). Technical oral presentations in English: Qualitative analysis of

Malaysian engineering undergraduates' sources of anxiety. International Conference on Education and

Educational Psychology (ICEEPSY 2011)

Polack-Wahl, J. A. (2000). It is time to stand up and communicate. Paper presented at the 30th ASEE/IEEE Frontiers in Education Conference, Kansas City USA, pp. 16-21.

Reinsch, L.N., \& Shelby, A.N. (1997). What communication abilities do practitioners need? Evidence from MBA students. Business Communication Quarterly, 6(4)0, 7-29.

Singleton, R. A. Jr., \& Straits, B. C. (2005). Approaches to social research. New York, N.Y.: Oxford University Press.

Sutton, N. (2002, August 9) Why can’t we all just get along? Computing Canada, (28)16, 20.

Van Horn, C.E (1995). Enhancing the connection between higher education and the workplace: A survey of employers. Denver, CO: State Higher Education Executive Officers Association.

Zareva, A. (2011). 'And so that was it': Linking adverbials in student academic presentations. RELC Journal, $42(1), 5-15$. 